\title{
Identifying Environmental Refuges ("Coldspots") from Infection by Batrachochytrium Dendrobatidis of Amphibians in Eastern Europe
}

\author{
Volodymyr Tytar ${ }^{1}$, Oksana Nekrasova ${ }^{1,{ }^{2}}{ }_{\llcorner}$Mihails Pupins ${ }^{2}$, Arturs Skute ${ }^{2}$, Oleksii Marushchak ${ }^{1 *}$ \\ Andris Čeirāns ${ }^{2}$, Iryna Kozynenko ${ }^{1}$ \\ 1 I. I. Schmalhausen Institute of Zoology, National Academy of Sciences of Ukraine, Kyiv, Ukraine; \\ oneks22@gmail.com \\ 2 Department of Ecology, Institute of Life Sciences and Technologies, Daugavpils University, Daugavpils, \\ Latvia; mihails.pupins@gmail.com \\ * Correspondence: ecopelobates@gmail.com; Tel.: +38-096-488-2670
}

\begin{abstract}
Amphibians are the most threatened group of vertebrates. While habitat loss poses the greatest threat to amphibians, a spreading fungal disease caused by Batrachochytrium dendrobatidis (Bd) is seriously affecting an increasing number of species. Although Bd is widely prevalent, there are identifiable heterogeneities in the pathogen's distribution that are linked to environmental parameters. Our objective was to identify conditions that affect the geographic distribution of this pathogen using species distribution models (SDMs), with a special focus on Eastern Europe. SDMs can help identify hotspots for future outbreaks of $\mathrm{Bd}$, but perhaps more importantly identify locations that may be environmental refuges ("coldspots") from infection. In general, climate is considered a major factor driving amphibian disease dynamics, but in particular temperature has received increased attention. Here, 42 environmental raster layers containing data on climate, soil and human impact were used. Mean annual temperature range (or 'continentality') was found to have the strongest constrain on the geographic distribution of this pathogen. Using the partial dependence visualization module in the R package 'embarcadero', a number of corresponding coldspots were identified.
\end{abstract}

Keywords: amphibians; coldspots; Batrachochytrium dendrobatidis; fungal diseases; infection; pathogen; distribution; GIS modelling.

\section{Introduction}

Amphibians are the most threatened group of vertebrates with a third of currently known species endangered with extinction and although habitat loss clearly poses the greatest threat to amphibians, a newly recognized fungal disease is seriously affecting an increasing number of species [1]. This disease caused by the chytrid fungus Batrachochytrium dendrobatidis (Bd) has been linked to the declines of amphibian species globally and represents the greatest documented loss of biodiversity attributable to a pathogen [2]. Although Bd is widely prevalent, there are identifiable heterogeneities in the pathogen's distribution that are linked to environmental parameters [3]. In this respect, species distribution models (SDMs) have proven to be useful tools for predicting $\mathrm{Bd}$ distribution and elucidating the importance of a wide range of environmental covariates considered to affect Bd occurrence. The first developed Bd SDMs were global in scope [4, 5]. Using SDMs, our objective was to identify conditions that constrain the geographic distribution of this pathogen in Eastern Europe in an aim to identify hotspots for future outbreaks of Bd, but perhaps more 
importantly identify locations that may be environmental refuges ("coldspots") from infection [6]. Undoubtedly, both aspects are essential for proactive conservation planning [7].

\section{Materials and Methods}

Localities for Bd were gathered from GBIF (https://www.gbif.org) and the literature [8, 9; etc.]. Because many uncertainties are associated with SDM projections, particularly when it comes to building a SDM for a species expanding its home range in a new area, we used for the analysis only records of European localities. In total there were 648 such records. These were filtered out by enforcing a distance of $50 \mathrm{~km}$ between records; we used this filtering process because ecological niche models are sensitive to sample bias [10]. In the end, the total number of records was reduced to 116. To build models, environmental values at localities of known occurrence are determined and then used to identify geographic regions that have similar combinations of environmental values. Several types of environmental variables at a geodetic resolution of 5 arc minutes have been used as proxy for the fundamental niche [11]: 1) the Bioclim dataset (https://www.worldclim.org/bioclim), 2) several eco-attributes, like: human fragmentation, -accessibility and -appropriation (https://databasin.org), 3) the ENVIREM dataset (https://envirem.github.io/), and 4) the Global Soil Dataset (http://globalchange.bnu.edu.cn/research/soilw)(see also: [12]). SDMs were generated by employing Bayesian additive regression trees (BART), a powerful machine learning approach. Running SDMs with BARTs has recently been greatly facilitated by the development of an R package, 'embarcadero' [13], including an automated variable selection procedure being highly effective at identifying informative subsets of predictors. Also the package includes methods for generating and plotting partial dependence curves and visualization called spatial partial dependence plots, which reclassifies predictor rasters based on their partial dependence plots, and show the relative suitability of different regions for an individual covariate. Habitat suitability values range from 0 to 1 . Model performance was assessed using measures of accuracy: the area under the receiver-operator curve (AUC, [14]) and the true skills statistic (TSS, [15]).

\section{Results}

Both measures of accuracy showed the SDM performed very well (AUC $=0.92$ and TSS $=0.73$ ). The automated variable selection procedure identified an informative subsets of predictors, of which important were continentality $\left({ }^{\circ} \mathrm{C}^{*} 10\right)$, minimum temperature of the coldest month $\left(\left({ }^{\circ} \mathrm{C}^{*} 10\right)\right.$, Thornthwaite's aridity index [16, 17], $\mathrm{pH}$ (measured in a calcium chloride solution), and human appropriation $[18,19]$. Temperature is considered one of the most important environmental factors driving chytridiomycosis [20], with its lower thermal limit being below $4^{\circ} \mathrm{C}$ [21]. Amongst the used covariates, continentality is perhaps the most distinguishable dimension of the climatic niche of $\mathrm{Bd}$ in the study area, featuring the seasonal amplitude in ambient temperature. From the picture (Figure 1) it is clear that large differences between low temperatures in the cold season and high temperatures in the hot season are limiting factors for the pathogen, with habitat suitability (the 'response') dropping from above 0.6 in the west of the continent to below 0.3 in the east (Figure 2). An indication that low temperatures limit the spread of $\mathrm{Bd}$ is the ascending character of the partial dependence curve plotted for the minimum temperature of the coldest month, showing a steep rise of habitat suitability (to over 0.5 ) on approaching the mark of $0 \mathrm{oC}$. Earlier bioclimatic variables associated with precipitation were found to make high contributions to SDMs considering Bd [6]. In our case Thornthwaite's aridity index, commonly used for measuring aridity of an area and based on both precipitation and temperature, showed better performance than most other bioclimatic variables, maybe because of its compound character. The partial dependence curve built for this index clearly highlights wet, humid and marginally moist sub-humid (values between 1 and 31, or slightly over 32) climates as suitable for the pathogen. Of soil features $\mathrm{pH}$ turned out to be the most contributing to the SDM. Outbreaks of chytridiomycosis may be affected by $\mathrm{pH}$, but the $\mathrm{pH}$ optimum $(\mathrm{pH} 6-7)$ for B. dendrobatidis is not outside common $\mathrm{pHs}$ of freshwater systems [21]. Our model indicated an 
optimum of around 6.5 where the suitability was the highest. Finally, human appropriation, the only human-related covariate selected for its contribution to the SDM. Human appropriation provides a useful measure of human intervention into the biosphere through the appropriation of net primary production. Our model explicity points towards areas of greater human intervention as areas more likely to be suitable for $\mathrm{Bd}$.

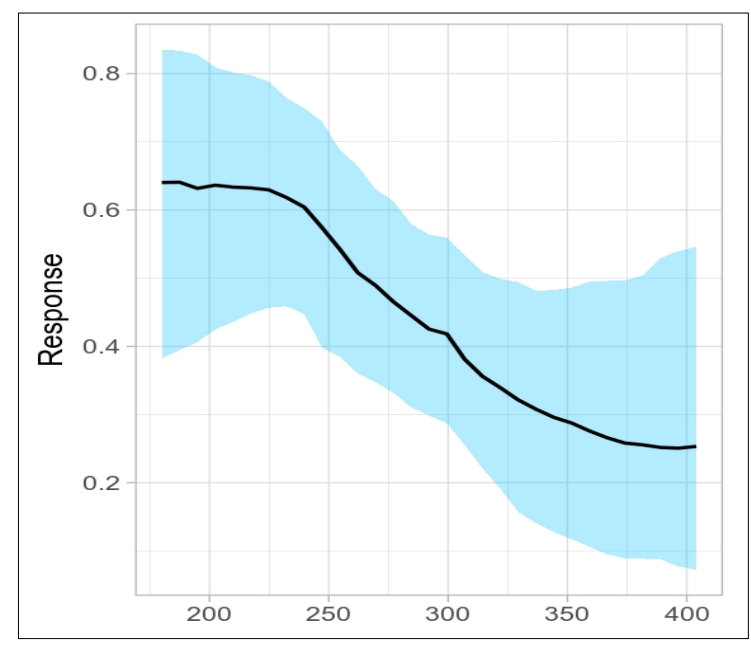

Figure 1. Partial dependence plot for 'continentality'; blue area $=95 \%$ confidence interval

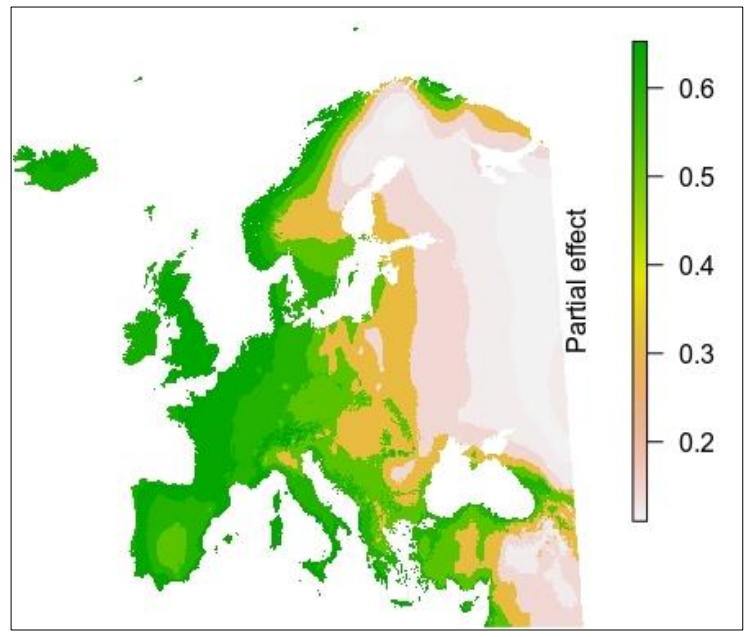

Figure 2. Spatial partial dependence plot for 'continentality', showing the relative suitability of different regions in Europe for Batrachochytrium dendrobatidis

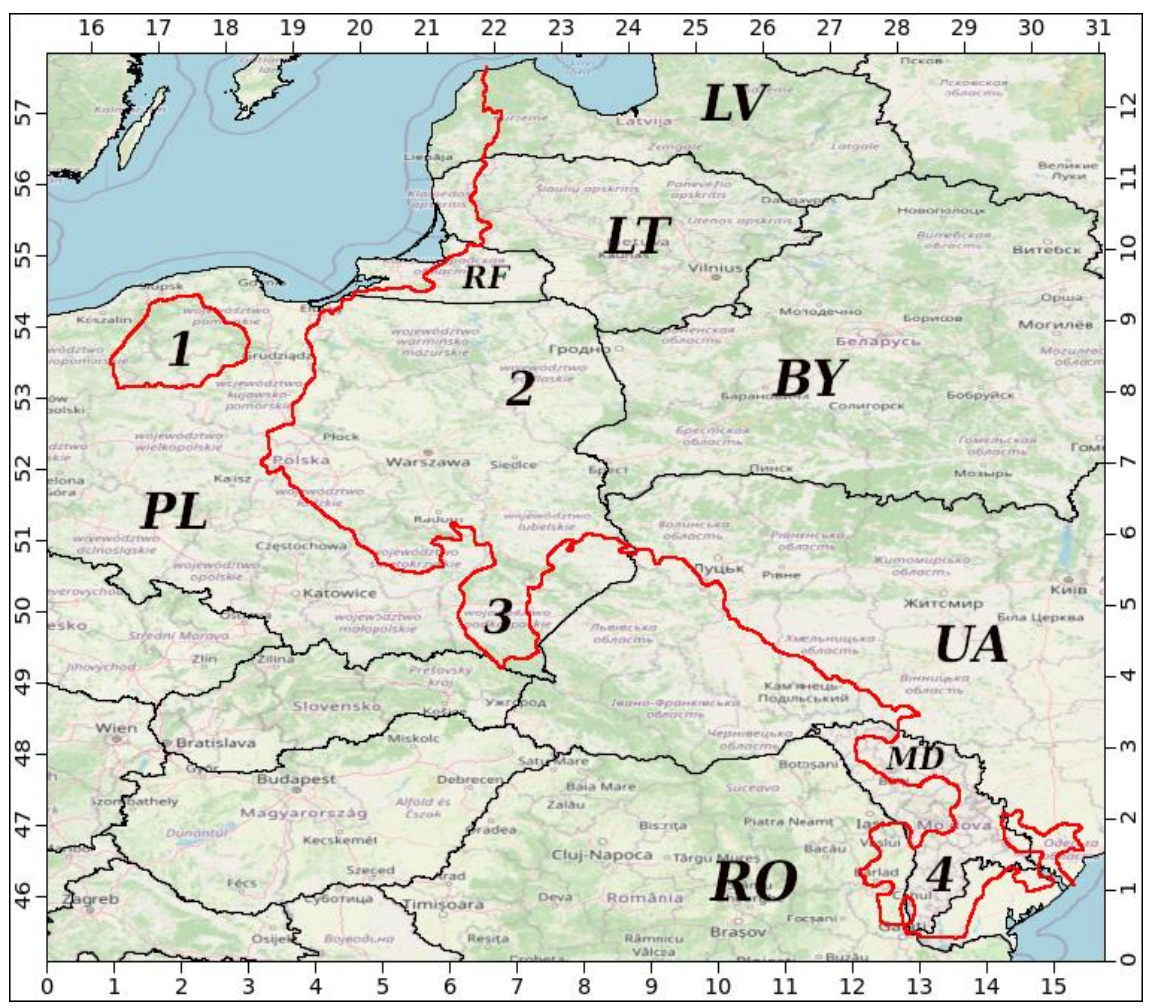

Figure 3. Map depicting contour lines (in red colour) delimiting areas in Eastern Europe where modelled habitat suitability (HS) for Batrachochytrium dendrobatidis is above or below the threshold of 0.2; coldspots (HS<0.2) along the major line are numbered: 1 - Northern Poland (enclave); 2 - NE Poland; 3 - Subcarpathia; 4 - Moldovan; country abbr.: BY - Belarus, LV - Latvia, LT - Lithuania, MD - Moldova, PL - Poland, RO - Romania, RF - Russian Federation, UA - Ukraine. 


\section{Discussion}

Using the SDM and an arbitrarily selected threshold of 0.2 , we identified locations that may be environmental refuges ("coldspots") for amphibians from infection by Bd in Eastern Europe (Figure 3). These in particular are areas close to the dividing threshold in Poland and Moldova (shared also with Romania and Ukraine) where adequate management and conservation plans for protecting amphibians have to be designed in the first place. Results of the modelling allow assuming that large portions of Latvia, Lithuania and Ukraine, Kaliningrad Province of the Russian Federation will not be favorable for the pathogen; in the case of Belarus this seems to hold for the entire country.

\section{Conclusion.}

SDMs, on one hand, predict the geographic extent of a species and on the other allow identifying the contribution of habitat covariates in explaining that distribution. Applied to $\mathrm{Bd}$, we find them useful to identify conditions that constrain the geographic distribution of this pathogen and identify locations that may be environmental refuges from infection.

Acknowledgments: We thank for cooperation the project "Pond aquaculture production and ecosystem service innovative research with modelling of the climate impact to tackle horizontal challenges and improve aquaculture sustainability governance in Latvia" (lzp-2020/2-0070) financed by Fundamental and Applied Research Projects (FLPP).

Author Contributions: Conceptualization, O.N., M.P. and V.T.; Data curation, O.N., M.P., A.S., A.Č. and I.K.; Formal analysis, O.N. V.T., O.M.; Funding acquisition, M.P., A.S., A.Č.; Investigation, O.N., M.P., O.M., I.K. and A.Č.; Methodology, O.N. and V.T.; Project administration, A.S., O.N., A.Č., and M.P.; Resources, O.N., M.P., and AČ; Software, O.N. and V.T.; Supervision, O.N., V.T., and M.P.; Validation, O.N., V.T., A.Č. and M.P.; Visualization, O.N., V.T., and M.P.; Writing-original draft and Writing - review \& editing, author: O.N., V.T., M.P., A.Č., O.M., A.S. and I.K.

Conflicts of Interest: The authors declare no conflict of interest.

\section{Abbreviations}

The following abbreviations are used in this manuscript:

SDM: species distribution model

BART: Bayesian additive regression trees

Bd: Batrachochytrium dendrobatidis

TSS: true skills statistic

AUC: area under the receiver-operator curve

\section{References}

1. IUCN, Conservation International, and NatureServe. 2008. An Analysis of Amphibians on the 2008 IUCN Red List <www.iucnredlist.org/amphibians>. Downloaded on 21 July 2020.

2. Scheele B. C., Pasmans F., Berger L., Martel A., Beukema W., Acevedo A. A., Burrowes P. A., Carvalho T., Catenazzi A., De la Riva I., Fisher M. C., Flechas S. V., Foster C. N., Frías-Álvarez P., Garner T. W. J., Gratwicke B., Guayasamin J. M., Hirschfeld M., Kolby J. E., Kosch T. A., La Marca E., Lindenmayer D. B., Lips K. R., Longo A. V., Maneyro R., McDonald C. A., Mendelson III J., Palacios-Rodriguez P., Parra-Olea G., Richards-Zawacki C. L., Rödel M.-O., Rovito S. M., Soto-Azat C., Toledo L. F., Voyles J., Weldon C., Whitfield S. M., Wilkinson M., Zamudio K. R., Canessa S. Amphibian fungal panzootic causes catastrophic and ongoing loss of biodiversity. Science, 2019, 363, 1459-1463. 
3. Fisher M.C., Garner T.W.J., Walker S.F. Global Emergence of Batrachochytrium dendrobatidis and Amphibian Chytridiomycosis in Space, Time, and Host. Annual Review of Microbiology 2009, 63(1), 291-310.

4. Rodder D., J. Kielgast J. Bielby S. Schmidtlein Bosch, J., Garner T. W. J., Veith M., Walker S., Fisher M. C., Lötters S. Global amphibian extinction risk assessment for the panzootic chytrid fungus. Diversity, 2009, 1, 52- 66. https://doi.org/10.3390/d1010052

5. Liu X., Rohr J. R., Li Y. M. Climate, vegetation, introduced hosts and trade shape a global wildlife pandemic. Proc. Biol. Sci., 2013, 280. doi: 10.1098/rspb.2012.2506.

6. Zumbado-Ulate H., García-Rodríguez A., Vredenburg V. T., Searle C. Infection with Batrachochytrium dendrobatidis is common in tropical lowland habitats: Implications for amphibian conservation. Ecol. Evol., 2019, 9, 4917-4930. https://doi.org/10.1002/ece3.5098.

7. Miller C.A., Tasse Taboue G. C., Ekane M. M. P., Robak M., Sesink Clee P. R., Richards-Zawacki C., Fokam E. B., Fuashi N. A., Anthony N. M. Distribution modeling and lineage diversity of the chytrid fungus Batrachochytrium dendrobatidis (Bd) in a central African amphibian hotspot. PLOS ONE, 2018, 13(6), e0199288. https://doi.org/10.1371/journal.pone.0199288.

8. Greenberg D. A., Palen W. J., Mooers, A. Ø. Amphibian species traits, evolutionary history and environment predict Batrachochytrium dendrobatidis infection patterns, but not extinction risk. Evol Appl., 2017, 10, 1130- 1145. https://doi.org/10.1111/eva.12520.

9. Schatz A. M., Kramer A. M., Drake J. M. Accuracy of climate-based forecasts of pathogen spread. R. Soc. opensci., 2017, 4, 160975. http://dx.doi.org/10.1098/rsos.160975.

10. Warren D. L., Seifert S.N. Ecological niche modeling in Maxent: the importance of model complexity and the performance of model selection criteria. Ecological Applications, 2011, 21, 335-342. https://doi.org/10.1890/10-1171.1.

11. Peterson A. T., Soberón J., Pearson R. G., Anderson R. P., Martinez-Meyer E., Nakamura M., Araújo M. Ecological niches and geographic distributions. Princeton N.J.: Princeton University Press, Princeton, USA, 2011; 314 pp.

12. Hulleman W. G., Vos R. A. Modeling Abiotic Niches of Crops and Wild Ancestors Using Deep Learning: A Generalized Approach. bioRxiv, 2019, 826347. doi: https://doi.org/10.1101/826347.

13. Carlson C. J. 'embarcadero': Species distribution modelling with Bayesian additive regression trees in $R$. Methods Ecol. Evol., 2020, Early View, 1-9.

14. Fielding A. H., Bell J. F. A review of methods for the assessment of prediction errors in conservation presence/absence models. Env. Conserv., 1997, 24(1),38-49.

15. Allouche O., Tsoar A., Kadmon R. Assessing the accuracy of species distribution models: prevalence, kappa and the true skill statistic (TSS). Journal of Applied Ecology, 2006, 43(6), 1223-1232. https://doi.org/10.1111/j.1365-2664.2006.01214.x

16. Thornthwaite C. W. The climate of North America according to a new classification. Geogr. Rev., 1931, 21 (4), 633-655.

17. Thornthwaite C. W. An approach toward a rational classification of climate. Geogr. Rev., 1948, 38(1), 55-94.

18. Imhoff M. L., Bounoua L. Exploring Global Patterns of Net Primary Production Carbon Supply and Demand Using Satellite Observations and Statistical Data. Journ. Geophys. Res., 2006, 111(D22), S12. http://dx.doi.org/10.1029/2006JD007377.

19. Krausmann F., Erb K. H., Gingrich S., Haberl H., Bondeau A., Gaube V., Lauk C., Plutzar C., Searchinger T. D. Global human appropriation of net primary production doubled in the 20th century. Proc. Natl. Acad. Sci. U.S.A., 2013, 110(25), 10324-10329. doi: 10.1073/pnas.1211349110.

20. Bradley P. W., Brawner M. D., Raffel T. R., Rohr J. R., Olson D. H., et al. Shifts in temperature influence how Batrachochytrium dendrobatidis infects amphibian larvae. PLOS ONE, 2019, 4(9), e0222237. https://doi.org/10.1371/journal.pone.0222237.

21. Piotrowski J. S., Annis S. L., Longcore J. E. Physiology of Batrachochytrium dendrobatidis, a chytrid pathogen of amphibians. Mycologia, 2004, 96(1), 9-15. pmid:21148822.

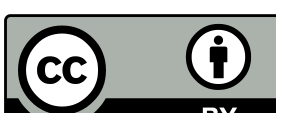

(C) 2020 by the authors; licensee MDPI, Basel, Switzerland. This article is an open access article distributed under the terms and conditions of the Creative Commons by Attribution (CC-BY) license (http://creativecommons.org/licenses/by/4.0/). 